\title{
Development of a Disaster Relief Logistics Model Minimizing the Range of Delivery Time
}

\author{
Kei Kokaji \\ Graduate School of System Design, \\ Tokyo Metropolitan University, 6-6, Asahigaoka, Hino, Tokyo 191-0065 Japan \\ Email: kokaji-kei@ed.tmu.ac.jp \\ Yasutaka Kainuma \\ Faculty of System Design, \\ Tokyo Metropolitan University, 6-6, Asahigaoka, Hino, Tokyo 191-0065 Japan \\ Email: kainuma@tmu.ac.jp (Corresponding Author)
}

\begin{abstract}
On March 11, 2011, the Great East Japan Earthquake (GEJE) attacked the North-Eastern Parts of Japan and the scale of the earthquake was the largest in recorded history in Japan. Despite Japan's great efforts in this disaster relief operation, relief goods did not reach the affected area. Managing disaster relief operations in the disaster situation like the GEJE is complex. Therefore, it became clear that the logistics system in the situation of a disaster had a lot of problems. In disaster situation like the GEJE, organizing the relief supply operations to afflicted people can be efficiently conducted. There are many disaster relief operations issues that need to be considered and resolved through logistics. Especially, it is very important that the distribution to the many victims is conducted equally. In this study, from the point of flow of distribution relief goods to the victims, we focus on the relationship between the shelter and the secondary collection point. The purpose of this study is to propose a logistics model that achieves the fair distribution for the many victims from the view point of the difference of the arrival time. In the earthquake, there were many routes that were unavailable and there was a limit to the number of cars that was available because of shortage of fuel. While considering these phenomena, we propose the logistics model that minimizes the range of the delivery time that the victims received relief goods from the transportation vehicles. Finally, in order to confirm the effectiveness of the proposed model, we perform the numerical experiments using the data of the Great East Japan Earthquake and the efficiency of the model is confirmed.
\end{abstract}

Keywords: vehicle routing, the Great East Japan Earthquake, disaster relief operations, range of delivery time

\section{INTRODUCTION}

On March 11, 2011, the Great East Japan Earthquake (GEJE) hit the North-eastern parts of Japan. Compared with the Great Hanshin Earthquake that occurred on January 17, 1995, the damage from the Great East Japan Earthquake was severe, and the latter was the greatest earthquake disaster in the history of Japan (see news from Kahoku Sinpou, 2011; National Police Agency HP; Hyogo Prefecture HP). Not only the vibration but also the tsunami caused by the earthquake brought considerable damage (report from Land, Infrastructure and Transportation Ministry, 2011). During this disaster event, various media reported that relief goods did not reach the affected areas (Kuze, 2011). It is believed that considerable damage caused stagnancy in the delivery of goods, and consequently, the hardship of the victims increased (Mine, 2011). After the Great East Japan Earthquake, the Japanese opinion of the disaster has been increasing. The same can be said about the logistics system and further research on the then delivery process has been conducted. Thus, a sound logistics system is critical for the smooth delivery of relief goods to victims. Unlike a commercial situation, where the main purpose of logistics is to reduce the cost, in a disaster situation, besides reducing the cost, logistics must consider numerous other factors. In particular, equal and fair distribution of relief goods to victims is crucial. The purpose of this study is to propose a logistics model that achieves fair distribution for victims from the viewpoint of the difference of arrival time.

\section{LITERATURE REVIEW}

Balcik et al. (2008) conducted a study that focuses on last-one-mile, that is, the final stage of delivery of relief goods. They suggest that in the final stage of delivery, the amount of relief supplies to be assigned to each shelter, delivery schedule, and patrol route of the vehicle are the primary factors to be considered. In the disaster situation, unlike the commercial situation, many routes become unavailable, the number of cars becomes limited, and the demand for relief goods significantly surpasses the supply. In this study, we propose a model that aims to resolve these issues in such a situation. The objective of this model is to minimize the unfulfilled demands of victims and the total cost of delivery. In this study, to consider the damage of the infrastructure, the cost of specific routes is set higher than the others. In addition, by considering multi-items and multiperiod, the model handles changes of the victim's needs that occur over time.

Campbell et al. (2008) assert that in a disaster, fastness and the fairness is very important. There are many existing tools for solving vehicle routing problems, and most of them focus on minimizing the total cost to conduct the delivery. They suggest that minimizing the total cost to conduct the delivery is not suitable to consider the fastness and fairness; furthermore, in a disaster, if the delivery aims at minimizing the total cost, the arrival of relief goods may be delayed 
extremely to reduce the cost, which consequently leads to suffering and life-and-death situations. They focus on the arrival time of relief goods and examine two alternative objective functions for the classic vehicle routing problems: one that minimizes the maximum arrival time and the other that minimizes the total arrival time.

\section{PROBLEM FORMULATION}

In this section, we introduce the notations and required parameters for the formulation. Subsequently, the decision variables of the mathematical model are defined. In previous studies, the model that considers the delivery time when relief supplies arrives at shelters has been proposed. However, the purpose of those models is minimizing the sum of arrival time and the disparity of the arrival time is not considered. Therefore, in this study, in order to consider the unfairness of the arrival time of each shelters, we proposed a model that minimizes the range of delivery time. Under chaotic circumstances in the event of a disaster, satisfaction level of victims does not increase linearly. In our study, we consider satisfaction level as utility function. Figure 1 shows the relationship between satisfaction level and the range of arrival time. In commercial situation, a few minutes improvement might be worthless. But in disaster situation, satisfaction level is increased remarkably, even just a minute improvement.

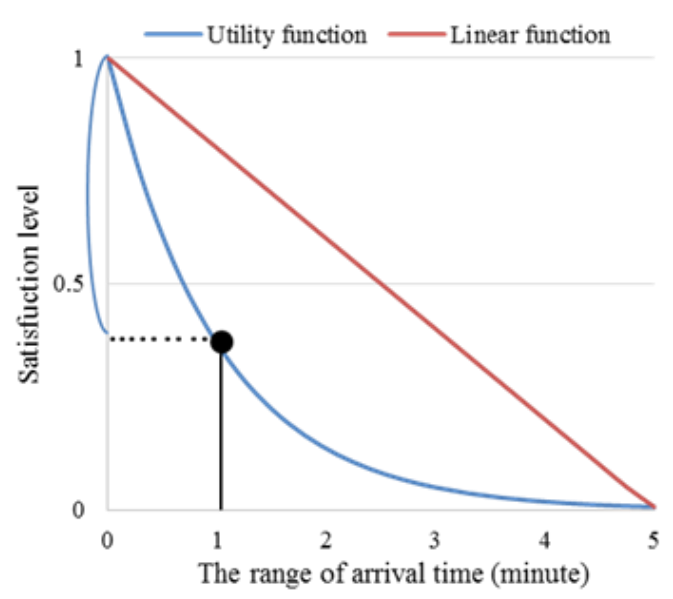

Figure 1 Relationship between satisfaction level and the range of arrival time.

$\begin{array}{cl}\text { Sets } & \\ N & \text { set of shelters } \\ V & \text { set of all nodes } \\ K & \text { set of cars } \\ \text { Parameters } \\ t_{i j} \quad \text { travel time between nodes } i \text { and } j \\ d_{i} \quad \text { demand of nodes } i \\ Q & \text { loading capacity of vehicles } \\ T & \text { sufficient large number } \\ \text { Decision } & \text { variables } \\ x_{i j k} & \text { binary variables equal to } 1 \text { if vehicle } k \text { travels } \\ & \text { from node } i \text { to node } j \\ a_{i k} & \text { arrival time at node } i \text { by car } k \\ a_{\min } & \text { fastest arrival time } \\ a_{\max } & \text { latest arrival time } \\ y_{i k} & \text { binary variables about the fastest arrival time }\end{array}$

Objective function

$$
\text { Minimize } \quad a_{\max }-a_{\min }
$$

The objective function in equation (1) minimizes the range of delivery time of relief goods from transportation vehicles.

Subject to

$$
\begin{array}{cc}
\sum_{k \in K} \sum_{j \in V} x_{i j k}=1 & \forall i \in N \\
\sum_{j \in V} x_{0 j k}=1 & \forall k \in K \\
\sum_{i \in V} x_{i h k}-\sum_{j \in V} x_{h j k}=0 & \forall h \in V, k \in K \\
\sum_{j \in V} x_{i 0 k}=1 & \forall k \in K \\
t_{i j}+a_{i k} \leq a_{j k}+T\left(1-x_{i j k}\right) & \forall i, j \in V, k \in K \\
a_{i k}-T\left(1-x_{0 i k}\right) \leq t_{0 i} & \forall i \in N, k \in K \\
\leq a_{i k}+T\left(1-x_{0 i k}\right) & \forall i \in N, k \in K \\
a_{\max } \geq a_{i k} & \forall i \in N, k \in K \\
a_{\min } \leq a_{i k}+T\left(1-y_{i k}\right) & \forall k \in K \\
\sum_{i \in N} d_{i} \sum_{j \in V} x_{i j k} \leq Q & \forall i, j \in V, k \in K \\
x_{i j k} \in\{0,1\} & \forall i \in N, k \in K \\
T y_{i k} \geq a_{i k} & \\
\sum_{k \in K} \sum_{i \in N} y_{i k}=n & \forall i \in N, k \in K \\
y_{i k} \in\{0,1\} &
\end{array}
$$

Constraint (2) ensures that each node is visited by a vehicle. Constraint (3) ensures that all of the vehicles must leave from the depot. Constraint (4) specifies that a vehicle arriving at node i must leave it. Constraint (5) specifies that all of the vehicles must return to the depot. Constraints (6) and (7) specify that a represents the appropriate arrival times. Constraint (8) indicates inequality related to the latest arrival time. Constraint (9) indicates inequality related to the fastest arrival time. Finally, Constraint (10) ensures that the total load per route must not exceed the loading capacity of vehicles.

Addictionaly, in order to examine the efficacy of the proposed model to conduct fair delivery in terms of arrival time of relief goods from the transportation vehicles, we perform a comparison with two classic models. One of them aims to minimize the total cost of transportation and the other aims to minimize the total arrival time. Equations (15) and (16) are their objective functions.

$\begin{array}{ll}\text { Minimize } & \sum_{i, j \in V} \sum_{k \in K} t_{i j} x_{i j k} \\ \text { Minimize } & \sum_{i \in N \in \in K} \sum_{i k} a_{i k}\end{array}$

\section{NUMERICAL EXPERIMENT}

\subsection{Case study 1}

In this section, a numerical experiment is conducted to examine the efficacy of the proposed model using data from the Great East Japan Earthquake. We focus on the number of shelters in Soma City, Fukushima Prefecture, an area affected by the Great East Japan Earthquake. We show the positional relationship between the North-eastern parts of Japan and Soma City, Fukushima Prefecture in Figure 2. 


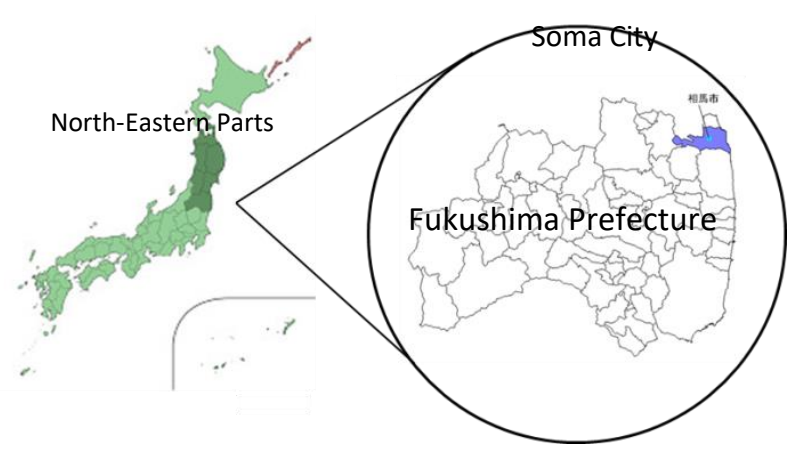

Figure 2 Positional Relationship Between the North-Eastern and Soma City

The number of shelters is set based on the research of Soeta et al. (2015). We regard a city hall of Soma City as a secondary collection point. We show the demand for each shelter in Table 1. During the Great East Japan Earthquake, under the influence of the collapse, crack, and liquefaction, many routes became unavailable, and consequently, the delivery of relief goods was delayed. In this kind of situation, using large vehicles such as $2 \mathrm{t}$ trucks and vans for delivery is not suitable. Therefore, in this study, the loading capacity of vehicles is set to $750 \mathrm{~kg}$. In addition, only one commodity is considered. In order to examine the changes of the value caused by changes in the number of vehicles, we change the number of available vehicles from 3 up to 8 . Figure 3 shows a map of Soma City quoted from Google Maps. We show the positional relationship between a secondary collection point and each shelter by putting marks on this map. A blue circle represents the location of a secondary collection point and green circles represent the location of each shelter. We show the travel time between each shelter in Table 2. The travel time between nodes $i$ and $j$ is set based on the value obtained by researching Google Maps. Figure 4 shows that the relationship between the number of vehicles and the range of delivery time of relief goods. Figure 5 shows the relationship between the number of vehicles and the total cost of transportation.

According to these figures, we found that the proposed model can minimize the range of delivery time. In addition, we found that the larger the number of vehicles, the smaller the value we got. But, according to Figure 5, we found that the largest value is obtained using the proposed model in terms of cost.

Figure 6 and Figure 7 shows the route of vehicles to deliver relief goods using the proposed model and the model aims to minimize the total arrival time when five vehicles can be used. Arrows represent the flow of vehicles.

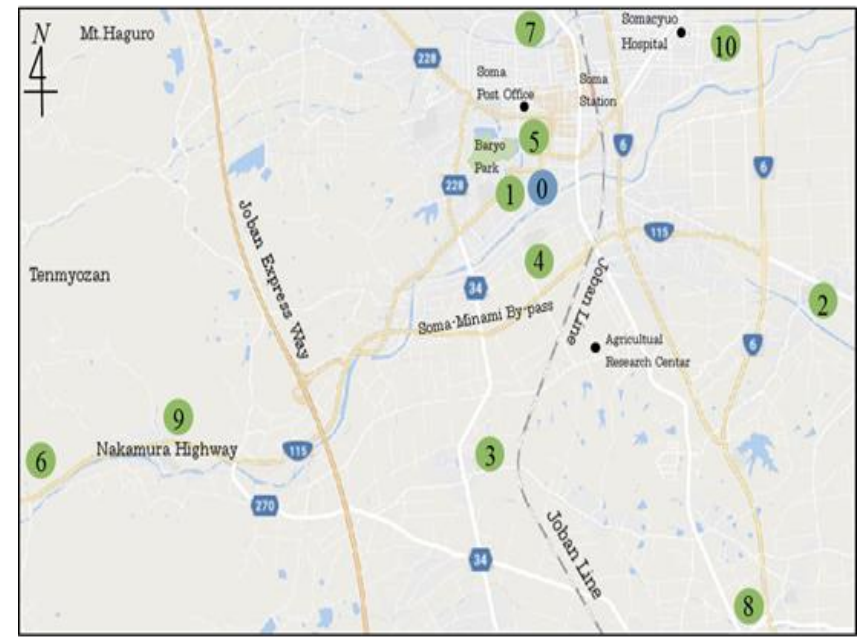

Figure 3 Positional Relationship Between the Secondary Collection Point and Shelters in Soma City

Table 1 Each Shelter's Demand (kg)

\begin{tabular}{|c|c|c|c|}
\hline Shelter's Name & Demand & Shelter's Name & Demand \\
\hline $\begin{array}{c}\text { 1. Nakamura first } \\
\text { primary school }\end{array}$ & 210 & $\begin{array}{c}\text { 6.The old man } \\
\text { diverticulum } \\
\text { house }\end{array}$ & 20 \\
\hline $\begin{array}{c}\text { 2.litoyo elementary } \\
\text { school }\end{array}$ & 70 & $\begin{array}{c}\text { 7.Hamanasu } \\
\text { welfare center }\end{array}$ & 230 \\
\hline $\begin{array}{c}\text { 3.Yahata elementary } \\
\text { school gymnasium }\end{array}$ & 70 & $\begin{array}{c}\text { 8.Nittaki } \\
\text { community } \\
\text { center }\end{array}$ & 30 \\
\hline $\begin{array}{c}\text { 4.Koyo junior high } \\
\text { school }\end{array}$ & 210 & $\begin{array}{c}\text { 9.Yamagami } \\
\text { community } \\
\text { center }\end{array}$ & 10 \\
\hline 5.Sport Arena Soma & 120 & $\begin{array}{c}\text { 10.Somahigashi } \\
\text { high school }\end{array}$ & 230 \\
\hline
\end{tabular}

NMinimizing the total cost $=$ Minimizing the total of arrival times - Proposed model

60
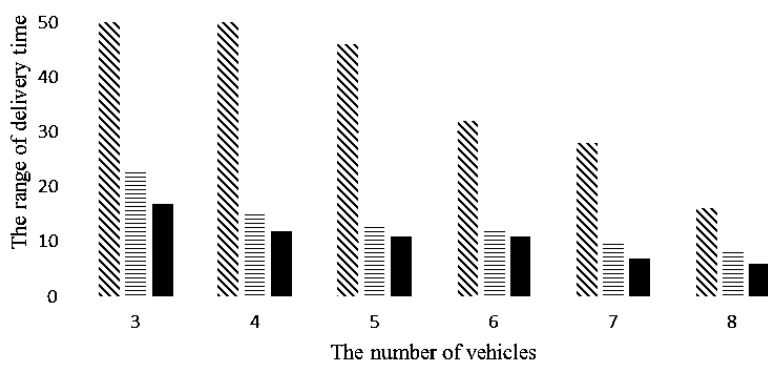

Figure 4 Relationship Between the Number of Vehicles and the Range of Delivery Time 


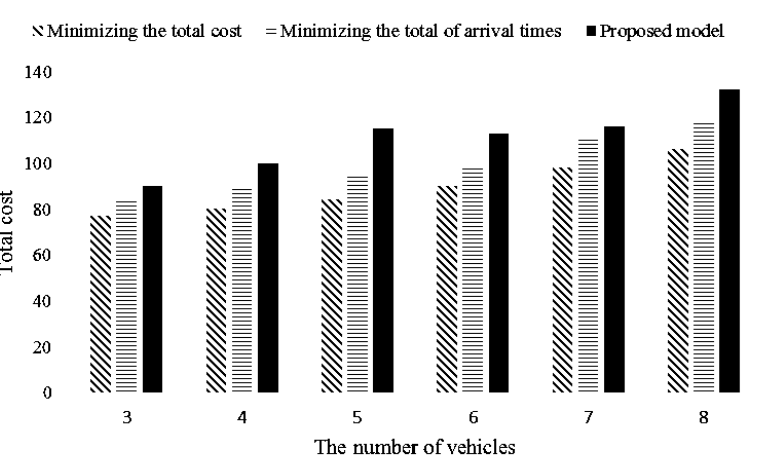

Figure 5 Relationship Between the Number of Vehicles and the Total Cost of Transportation

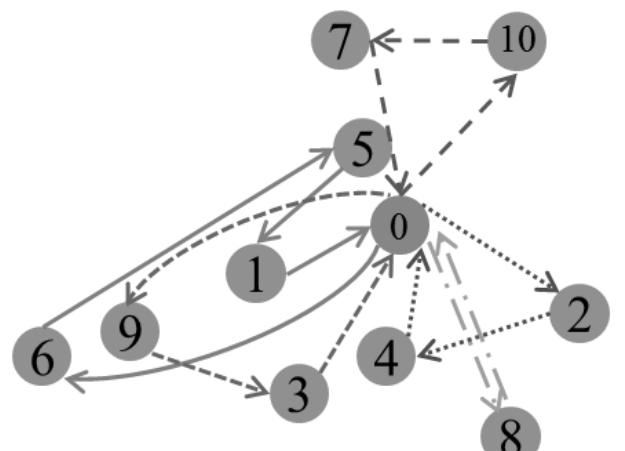

Figure 6 Route of Vehicles Using the Proposed Model

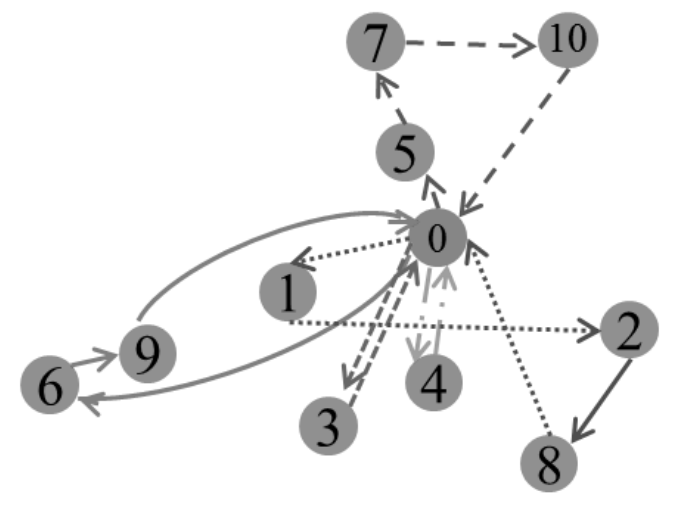

Figure 7 Route of Vehicles Using the Model Aims to Minimize the Total Arrival Time
From these figures, we can read the characteristics of using each model. we find that the delivery to the shelter near the secondary collection point such as Nakamura first primary school, Sport Arena Soma and Yahata elementary school is prioritized using the model aims to minimize the total arrival time. However, as a result, there is possibility that the arrival time of some shelters may be late. On the other hand, we find that the shelter near the secondary collection point is not prioritized necessarily using the proposed model. In our model, vehicles tend to go the shelter far from secondary collection point such as The old man diverticulum house, Iitoyo elementary school and Somahigashi high school at first. As a result, the range of the delivery time is redused.

\subsection{Case study 2}

Next, we carry out a numerical experiment using other regions' data to examine how the results differ regionally. As in the Soma City case study, we use data regarding the Great East Japan Earthquake.

We focus on the number of shelters in Noda Village, Iwate Prefecture. We regard a city hall of Noda Village as the secondary collection point. We show the positional relationship between the Northeast parts of Japan and Noda Village, Iwate Prefecture, in Figure 8. We show the demand of each shelter in Table 3. Figure 9 shows a map of Noda Village obtained from Google Maps. We show the positional relationship between the secondary collection point and each shelter by placing marks on this map. The blue circle represents the secondary collection point and the green circles represent the shelters. We show the travel time between each shelter in Table 4. The travel time between nodes $i$ and $j$ is set based on the value obtained from Google Maps. Other parameters are the same as in Case Study 1. Figure 10 shows the relationship between the number of vehicles and the delivery time range of relief goods. Figure 10 shows the relationship between the number of vehicles and total transportation cost. Figures $\mathbf{1 2}$ and $\mathbf{1 3}$ show the routes vehicles use to deliver relief goods using the proposed model; the model aims to minimize total delivery time when five vehicles are used. The arrows represent the flow of vehicles.

Table 2 Travel time (minutes)

\begin{tabular}{|l|c|c|c|c|c|c|c|c|c|c|c|}
\hline & $\mathbf{0}$ & $\mathbf{1}$ & $\mathbf{2}$ & $\mathbf{3}$ & $\mathbf{4}$ & $\mathbf{5}$ & $\mathbf{6}$ & $\mathbf{7}$ & $\mathbf{8}$ & $\mathbf{9}$ & $\mathbf{1 0}$ \\
\hline 0. Secondary collection point & & & & & & & & & & & \\
\hline 1. Nakamura first primary school & 1 & & & & & & & & & & \\
\hline 2. litoyo elementary school gymnasium & 10 & 5 & & & & & & & & & \\
\hline 3. Yahata elementary school gymnasium & 7 & 7 & 11 & & & & & & & & \\
\hline 4. Koyo junior high school gymnasium & 8 & 7 & 10 & 9 & & & & & & & \\
\hline 5. Sport Arena Soma & 1 & 1 & 10 & 9 & 9 & & & & & & \\
\hline 6. The old man diverticulum house & 9 & 8 & 13 & 10 & 11 & 9 & & & & & \\
\hline 7. Hamanasu welfare center & 4 & 4 & 11 & 11 & 11 & 3 & 11 & & & & \\
\hline 8. Nittaki community center & 9 & 10 & 7 & 8 & 11 & 10 & 10 & 12 & & & \\
\hline 9. Yamagami community center & 9 & 8 & 13 & 10 & 11 & 9 & 2 & 11 & 11 & & \\
\hline 10. Somahigashi high school & 9 & 10 & 13 & 15 & 13 & 10 & 17 & 10 & 15 & 17 & \\
\hline
\end{tabular}




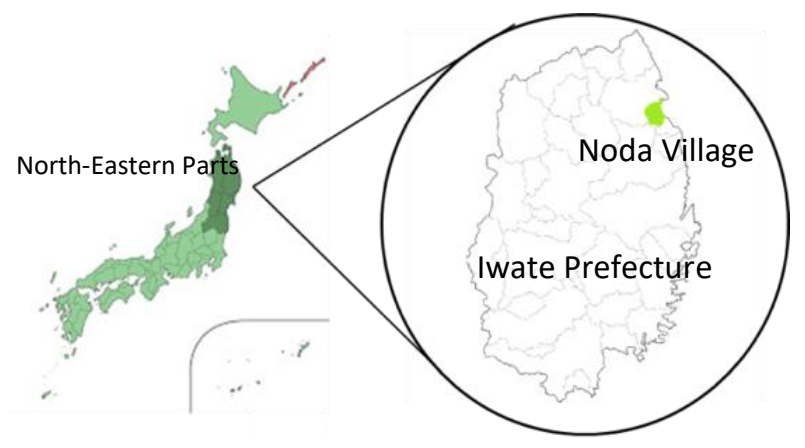

Figure 8 Positional Relationship Between the North-Eastern and Noda Village

Table 3 Each shelter's demand (kg)

\begin{tabular}{|l|c|l|c|}
\hline Shelter's Name & Demand & \multicolumn{1}{|c|}{ Shelter's Name } & Demand \\
\hline $\begin{array}{l}\text { 1.Noda ementary } \\
\text { school }\end{array}$ & 262 & $\begin{array}{l}\text { 6.Niiyama } \\
\text { firefighting } \\
\text { station }\end{array}$ & 46 \\
\hline $\begin{array}{l}\text { 2.Noda junior high } \\
\text { school }\end{array}$ & 296 & 7. Eboshiso & 341 \\
\hline $\begin{array}{l}\text { 3.Kuji industry high } \\
\text { School }\end{array}$ & 214 & $\begin{array}{l}\text { 8.Maita community } \\
\text { center }\end{array}$ & 261 \\
\hline \begin{tabular}{l} 
4.Kaizoin \\
\hline 5.Nakahira community \\
center
\end{tabular} & 89 & $\begin{array}{c}\text { 9.Niiyama nursery } \\
\text { school }\end{array}$ & 28 \\
\hline
\end{tabular}

Table 3 Travel Time (minutes)

\begin{tabular}{|l|c|c|c|c|c|c|c|c|c|c|c|}
\hline & $\mathbf{0}$ & $\mathbf{1}$ & $\mathbf{2}$ & $\mathbf{3}$ & $\mathbf{4}$ & $\mathbf{5}$ & $\mathbf{6}$ & $\mathbf{7}$ & $\mathbf{8}$ & $\mathbf{9}$ & $\mathbf{1 0}$ \\
\hline 0. Secondary collection point & & & & & & & & & & & \\
\hline 1. Noda elementary school & 1 & & & & & & & & & & \\
\hline 2. Noda junior high school & 10 & 5 & & & & & & & & & \\
\hline 3. Kuji industry high School & 7 & 7 & 11 & & & & & & & & \\
\hline 4. Kaizoin & 8 & 7 & 10 & 9 & & & & & & & \\
\hline 5. Nakahira community center & 1 & 1 & 10 & 9 & 9 & & & & & & \\
\hline 6. Niiyama firefighting station & 9 & 8 & 13 & 10 & 11 & 9 & & & & & \\
\hline 7. Eboshiso & 4 & 4 & 11 & 11 & 11 & 3 & 11 & & & & \\
\hline 8. Maita community center & 9 & 10 & 7 & 8 & 11 & 10 & 10 & 12 & & & \\
\hline 9. Niiyama nursery school & 9 & 8 & 13 & 10 & 11 & 9 & 2 & 11 & 11 & & \\
\hline 10. Nakazawa community center & 9 & 10 & 13 & 15 & 13 & 10 & 17 & 10 & 15 & 17 & \\
\hline
\end{tabular}

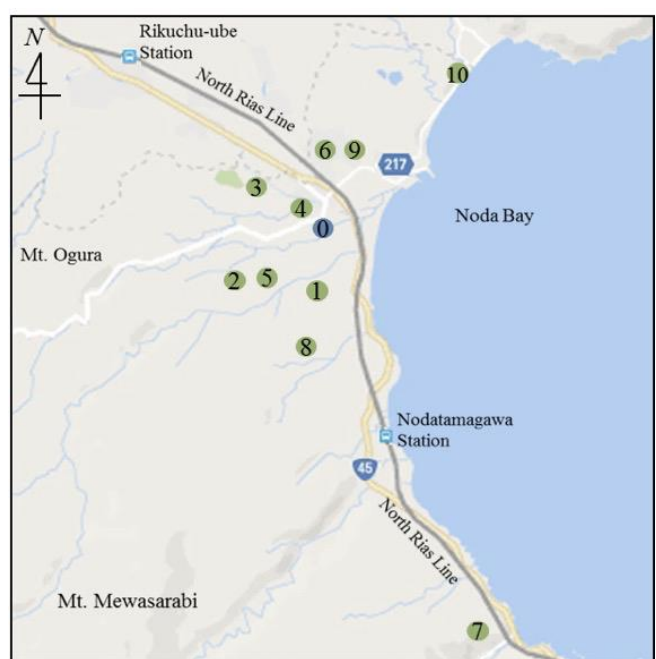

Figure 9 Positional Relationship Between the Secondary Collection Point and Shelters in Noda Village

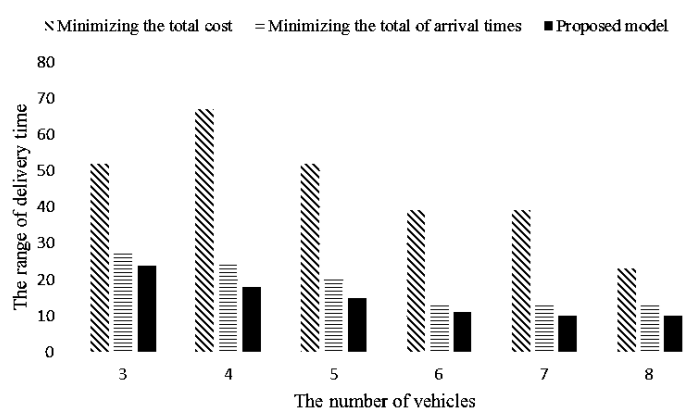

Figure 10 Relationship Between the Number of Vehicles and the Range of Delivery Time 


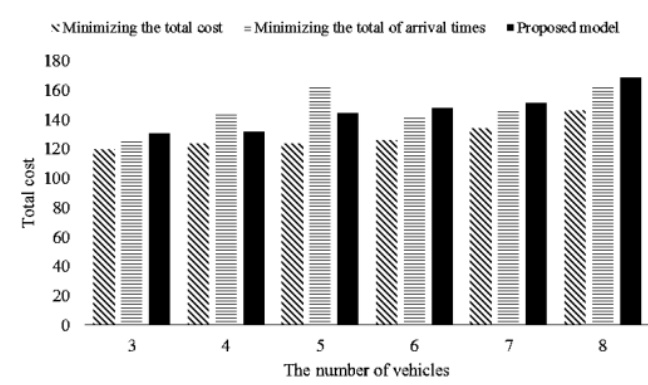

Figure 11 Relationship Between the Number of Vehicles and the Total Cost of Transportation

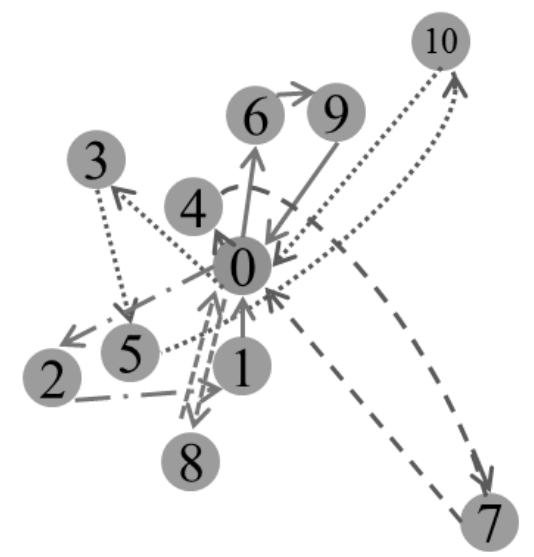

Figure 12 Route of Vehicles Using the Proposed Model

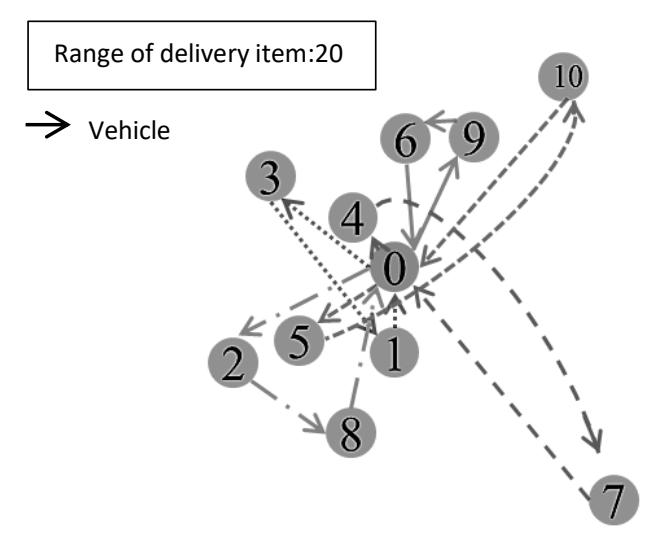

Figure 13 Route of Vehicles Using the Model Aims to Minimize the Total Arrival Time

From these figures, as in the Soma City case study, we can obtain the smallest value of the delivery time range using the proposed model. Additionally, a similar trend is exhibited by transportation cost. When we use the proposed model, we can conduct optimal delivery in terms of the arrival time of relief goods. However, the total cost of the proposed model is higher compared to the other model.

From these figures, we can see that delivery from the secondary collection point closest to the shelter is not necessarily prioritized in the proposed model. However, delivery to the shelter near the secondary collection point is prioritized using the model, aiming to minimize total arrival time. We find that we can reduce differences in delivery times using the proposed model. In disaster circumstances, even a few minutes of improvement in the arrival time can result in increased satisfaction. Therefore, we think that the proposed model can facilitate optimal delivery in terms of the arrival time of relief goods for the victims.

\section{CONCLUSION}

In this study, we proposed a humanitarian logistics model that minimizes the range of delivery time of relief goods. We performed numerical experiments to examine the efficacy of the proposed model using data from the Great East Japan Earthquake. In this numerical experiments, we consider satisfaction level as utility function. We assume that in a disaster situation, satisfaction level of victims does not increase linearly and satisfaction level is increased remarkably, even just a minute improvement. Using proposed model, we can conduct fair delivery in terms of the arrival time of relief goods. When we use proposed model, vehicles tend to go the shelter far from secondary collection point at first. We performed experiments for two foreign regions. In either case, similar trends were shown. However, the total cost of the proposed model is higher than the other model. We found that the larger the number of vehicles, the smaller the value of the range of delivery time. We also focused on the relationship between the shelter and the secondary collection point. However, to analyze a more realistic situation, we should consider not only the last mile but also the earlier phases. We plan to continue our research considering the delivery of bigger networks and analyzing the situation where the demand significantly surpasses the supply of relief goods. In addition, we should propose the model that can evaluate the satisfaction level of victims with indicators other than arrival time of relief goods.

\section{ACKNOWLEDGEMENTS}

This research is partially supported by the Grant-in-Aid for Scientific Research (c), number 26350428 from the Japan Society for Promotion of Science (JSPS).

\section{REFERENCES}

Afshar, A., Haghani, A. (2012). Modeling integrated supply chain logistics in real-time large-scale disaster relief operations. Socio-Economic Planning Sciences, 46, pp. 327-338

Apte, A. (2009). Humanitarian Logistics: A New Field of Research and Action, now Publishers Inc.

Balcik, B., Beamon, B. M., Smilowiz, K. (2008). Last mile distribution in humanitarian relief. Journal of Intelligent Transportation Systems, 48 (2), pp. 51-63.

Campbell, A. M., Vandenbussche, D., Herman,W. (2008). Routing for relief efforts. Transportation Science, 42 (2), pp. 127-145.

Google Map: https://maps.google.co.jp/ (10 February 2017)

Hanaoka,S. (2013). Literature review of humanitarian logistics problems and issues in the Great East Japan Earthquake. Journal of the Japan Society of Logistics, (21), pp. 373-376 (in Japanese).

Huang, M., Smilowitz, K., and Blcik, B. (2012) Models for relief routing: equity, efficiency and efficacy. Transportation Research Part E, 48, pp. 2-18

Hyogo Prefecture HP: http://web.pref.hyogo.jp/ (5 February 2016)

Japanese Logistics Society. (2011). Logistics of disasters Why does relief supplies not arrive - (preliminary 
report version). Emergency Symposium of the Kanto Subcommittee of the Japanese Logistics Association, (1), pp. 1-8 (in Japanese).

Kahoku Sinpou., (2011) Special reduced printing version, 1 month notation of 3.11 Great East Japan Earthquake, Tokyo : TAKESHOBO Co., Ltd (in Japanese).

Kuze, H. (2011). Logistics planning for disaster prevention. Urban Planning Papers, 3 (60), pp. 87-9 (in Japanese).

Kuze, H. (2011). The role of the OR to expect in relief supplies and reconstruction plan. Operations Research, 56 (12), pp. 698-701 (in Japanese).

Land, Infrastructure and Transportation Ministry, (2011). Correspondence in the Great East Japan Earthquake and logistics. Study Group Third materials on disaster emergency measures in the Great East Japan Earthquake.

Mine, T. (2011). Delay of the emergency cargo and the fact at the Great East Japan Earthquake. Logistics Studies 56, pp. 16-21 (in Japanese).

National Police Agency HP: http://www.npa.go.jp (5 February 2016)

Noda Village, Iwate Prefecture HP: http://www.vill.noda.iwate.jp/ (10 February 2017)

Özdamar, L., Ekinci, E. Kücükyazici, B. (2004). Emergency Logistics Planning in Natural Disasters, Annals of Operations Research, 129, pp.217-245

Pujawan, I. N., Kurniati, N. and Wessiani, N. A. (2009). Supply chain management for Disaster Relief Operations: principles and case studies. International Journal of Logistics Systems and Management, 5 (6), pp. 679-692.
Sheu, J. B. (2007). An emergency logistics distribution approach for quick response to urgent relief demand in disasters. Transportation Research Part E, 43 (6), pp. 687-709.

Shirou, I. (2011). About emergency supplies transportation by the all Japan truck Association. Logistics problem Research, 56, pp. 2-6 (in Japanese).

Soeta, H., Kabata, M., Kainuma, Y. (2015). Development of a logistics model for disaster relief operations. Journal of Japan Industrial Management Association, 66 (1), pp. 23-29 (in Japanese).

Soma City, Fukushima Prefecture HP: http://www.city.soma.fukushima.jp/ (10 February 2017)

Tanaka, T. (2012). Toward the construction of emergency relief supplies logistics system - Lessons learned from the Great East Japan Earthquake. Japan Information and Management Journal, 32 (2), pp. 20-32 (in Japanese).

Tomasini, R. M. and Van Wassenhove, L. N. (2009). From preparedness to partnerships: Case study research on humanitarian logistics. International Transactions in Operational Research, 16, pp. 549-559

Xu, L., Beamon, B. M. (2006). Supply chain coordination and cooperation mechanisms: an attribute-based approach. Journal of Supply Chain Management, 42 (1), pp. 4-12.

Yano, Y. (2011). Problems and challenges of supply of emergency relief supplies in the Great East Japan Earthquake. Logistics Problem Research, 56, pp. 11-15 (in Japanese).

Key Kokaji is a student at the Graduate School of System Design, Tokyo Metropolitan University, Japan.

Yasutaka Kainuma is associate professor of Operations Management in Department of Management Systems Engineering, Faculty of System Design, Tokyo Metropolitan University, Japan. He received a Ph.D. from School of Science and Technology, Meiji University. His research interests include supply chain management, closed-loop supply chain, sustainable operations and remanufacturing. He won the best paper award of the 21th ICPR (2011) and the outstanding paper award of the 14th APIEMS Conference (2013). 